\title{
Synthesis of Star Polymers of Styrene and Alkyl (Meth)acrylates from a Porphyrin Initiator Core via ATRP
}

\author{
L. R. Hermann High, Simon J. Holder,* and Hazel V. Penfold \\ Functional Materials Group, School of Physical Sciences, University of Kent, Canterbury, \\ Kent, CT2 7NH, U.K.
}

Received December 15, 2006; Revised Manuscript Received July 6, 2007

\begin{abstract}
A free-base tetrabromoporphyrin, 15,20-tetrakis(4-(2-methyl-2-bromopropoxy)phenyl)-21H,23Hporphine (2), was synthesized in high yield (91\%) by the esterification of 5,10,15,20-tetrakis(4-hydroxyphenyl)$21 \mathrm{H}, 23 \mathrm{H}$-porphine (1) with 2-bromo-2-methylpropanoyl bromide. The free-base porphyrin (2) was demonstrated to be suitable as an initiator for atom transfer radical polymerization (ATRP) of methyl methacrylate giving porphyrin-core star-poly(methyl methacrylate) with conversions of up to $98 \%\left(\mathrm{Cu}^{\mathrm{I}} \mathrm{Br}, N\right.$-( $n$-propyl)-2-pyridylmethanimine, toluene, $90{ }^{\circ} \mathrm{C}$ ). UV-vis spectroscopic analysis demonstrated that a degree of complexation of $\mathrm{Cu}$ (II) by the porphyrin core occurred during the polymerization. To avoid $\mathrm{Cu}$ (II) complexation, zinc(II) 10,15,20-tetrakis(4-(2-methyl-2-bromopropoxy)phenyl)-21H,23H-porphine (4) was synthesized from the free-base porphyrin (2) and employed as an initiator in the ATRP of MMA, giving the corresponding Zn porphyrin-core star-PMMA. The free-base porphyrin (2) was also employed as an initiator for the polymerization of styrene, methyl acrylate, butyl methacrylate, octadecyl acrylate and the copolymerization of isobutyl methacrylate (IBMA) and trifluoroethyl methacrylate (TFEMA), in all cases giving star polymers with conversions of 33-87\%. Basic hydrolysis of a porphyrin-core star-polystyrene polymer cleaved the ester linkages about the porphyrin, liberating the individual polystyrene chains which had a number-average molecular weight approximately one-fourth that of the precursor star polymer and a narrow polydispersity index $\left(M_{\mathrm{w}} / M_{\mathrm{n}}=1.15\right)$ thereby demonstrating efficient initiation from the porphyrin core. Palladium(II) 10,15,20-tetrakis(4-(2-methyl-2-bromopropoxy)phenyl)-21H,$23 \mathrm{H}$-porphine (3) was synthesized from the free-base porphyrin (2) and employed as an initiator in the ATRP of MMA but the polymerization was completely inhibited. Pd(II) was introduced into the star polymer cores by heating either a solution of the porphyrin-core star-PMMA or the $\mathrm{Zn}$ porphyrin-core star-PMMA with $\mathrm{Pd}^{\mathrm{II}} \mathrm{Cl}_{2}$ in benzonitrile. $\mathrm{Pt}(\mathrm{II})$ was introduced into a star polymer core by heating a solution of the Zn porphyrin-core starPIBMA-co-TFEMA with $\mathrm{Pt}^{\mathrm{II}} \mathrm{Cl}_{2}$ in benzonitrile. UV-vis spectroscopic analysis confirmed the synthesis of Pd(II) and Pt(II) porphyrin complexes and photoluminescent spectroscopy confirmed the luminescent properties of the materials.
\end{abstract}

\section{Introduction}

Metalated porphyrins have long been of interest as the active luminophores in optical oxygen-sensing systems as a result of both their luminescent yields and the sensitivity of the intensity and/or lifetimes of their emissions to environmental conditions. ${ }^{1}$ They have been particularly effective as oxygen sensing materials in pressure-sensitive paints where luminescent response is directly proportional to the local oxygen concentration which in turn depends on local pressure. ${ }^{2}$ However the solubility of porphyrins in many polymers can be low which can lead to aggregation and/or poor dispersion of the luminophores with resulting quenching, poor sensitivity and/or and reproducibility in local pressure measurements. Furthermore, the long-term stability of the luminescent thin films may be adversely affected by leaching of dye material embedded in the polymer thin films, a factor that is of particular importance for systems that are of potential use in biomedical applications. ${ }^{3}$ One approach to improving solubility and dispersibility of porphyrins in polymer thin films has been the synthesis of polymerizable monomer units bearing pendant porphyrins that can be covalently incorporated into the polymer in question. ${ }^{4}$ However this approach is synthetically demanding and consequently expensive in that it requires the synthesis of monofunctionalized porphyrins in the first instance. While monofunctional precursors are commercially available, they are up to four or five times as expensive

* To whom correspondence should be addressed. E-mail: S.J.Holder@kent.ac.uk. (per gram) than the equivalent tetrafunctional porphyrins as a consequence of the mixed products resulting from the synthesis of asymmetric porphyrins. The utilization of contemporary controlled radical polymerization techniques allows for the direct covalent attachment of vinyl polymer chains to a variety of functional molecular structures by employing these structures as initiators in the polymerization process. Of particular versatility is atom transfer radical polymerization (ATRP) which employs activated bromides or chlorides (typically) as initiators. ${ }^{5}$ It was envisaged that by using standard esterification techniques a tetrabromoporphyrin could be synthesized that would allow for the ATRP of a range of monomers and the ready solubilization of metal porphyrin based star polymers into polymer thin films. In addition to giving functioning and durable luminescent materials immediately suitable for application in pressuresensitive paints, such materials could also find uses in areas attracting increasing interest such as the ink-jet printing of luminescent metallopolymers. ${ }^{6}$ The synthesis by ATRP of star polymers from a range of initiators ${ }^{7}$ and the synthesis of metallopolymers from transition metal ligand based initiators ${ }^{8}$ has been performed by a number of groups, but to date there have only been two examples of ATRP from porphyrin initiators and this is the first example of the synthesis of well-defined fluorescent porphyrin-core star polymers by this approach. ${ }^{9}$ This paper describes a generic ATRP based methodology for the synthesis of star polymers from vinyl monomers and porphyrin initiators. 


\section{Experimental Section}

Materials. 5,10,15,20-tetrakis(4-hydroxyphenyl)-21H,23H-porphine (dye content 95\%) (1), 2-bromo-2-methylpropionyl bromide (98\%), copper(I) bromide (99\%), copper(II) bromide (99\%) triethylamine (99\%), and 15-crown-5 were purchased from Aldrich and used without further purification. Methyl methacrylate, methyl acrylate, butyl methacrylate, styrene, and 2,2,2-trifluoroethyl methacrylate (all 99\%) were purchased from Aldrich and passed through a short column of alumina to remove inhibitors prior to use. $2,2^{\prime}$ Bipyridine (99\%), 1,1,4,7,7-pentamethyldiethylenetriamine (99\%) and zinc(II) bromide (98\%) were purchased from Acros and used without further purification. Isobutyl methacrylate (99\%) was purchased from Acros and passed through a short column of alumina to remove the inhibitor prior to use. Palladium(II) chloride and platinum(II) chloride were purchased from Fluka and used without further purification. $\alpha, \alpha^{\prime}$-azoisobutyronitrile was purchased from Molekula and used without further purification. THF and toluene were purchased from Fisher and predried over $\mathrm{MgSO}_{4}$, dried over $\mathrm{Na}$ wire and then distilled under $\mathrm{N}_{2}$ over $\mathrm{Na}$ (and in the case of THF, benzophenone) immediately prior to use. $N$-(n-propyl)-2pyridylmethanimine and $N$-(n-octyl)-2-pyridylmethanimine were synthesized as reported in the literature. ${ }^{10}$

Poly(isobutyl methacrylate-co-trifluoroethyl methacrylate) (IBMAco-TFEMA), for use in paint formulations was synthesized by a standard free radical polymerization technique, using $\alpha, \alpha^{\prime}$ azoisobutyronitrile as an initiator and a 1:1 molar ratio of IBMA: TFEMA monomers in toluene at $80{ }^{\circ} \mathrm{C}$. The IBMA-TFEMA copolymer contained $52 \mathrm{~mol} \%$ IBMA and $48 \mathrm{~mol} \%$ TFEMA with $M_{\mathrm{n}}=29450$ and $M_{\mathrm{w}} / M_{\mathrm{n}}=1.75$.

Analysis. ${ }^{1} \mathrm{H}$ and ${ }^{13} \mathrm{C}$ NMR were recorded with a JEOL GX$270 \mathrm{FT}$ at $270 \mathrm{MHz}$ in $\mathrm{CDCl}_{3}$ solutions at $30{ }^{\circ} \mathrm{C}$. Spectra were interpreted with JEOL Systems Spec NMR 1.2.0 software. Monomer conversion was followed with ${ }^{1} \mathrm{H}$ NMR by following the change in relative integral ratios between monomer and polymer signals. Molecular weight parameters were measured with equipment supplied by Polymer Laboratories, Ltd. All measurements were carried out on samples in tetrahydrofuran (THF) at $40{ }^{\circ} \mathrm{C}$ with two $300 \times 7.5 \mathrm{~mm}$ PLgel $5 \mu \mathrm{m}$ Mixed-C columns equipped with an LC 1120 high-performance liquid chromatography (HPLC) pump and a Shodex RI-101 refractive index detector and a Knauer K-2600 variable dual wavelength UV-vis detector. The instrumentation was calibrated with poly(methyl methacrylate) (PMMA) and polystyrene (PS) standards supplied by Polymer Laboratories, Ltd.

UV - vis spectra were recorded on a Unicam UV500 spectroscope at $20{ }^{\circ} \mathrm{C}$ in dichloromethane at concentrations of $0.1 \mathrm{mg} \mathrm{mL}^{-1}$. Fluorescence spectra were recorded on a Perkin-Elmer LS50B spectrophotometer from THF solutions at concentrations of $0.1 \mathrm{mg}$ $\mathrm{mL}^{-1}$ or from thin films in IBMA-co-TFEMA matrices at $1 \mathrm{wgt} \%$ concentrations on quartz slides at $20^{\circ} \mathrm{C}$. MALDI- and LDI-TOF mass spectra were obtained from a Bruker ultraflex mass spectrometer. The matrices for MALDI-TOF (reflectron) were transindole acrylic acid (Acros, 98\%) for the polymethacrylate samples and dithranol (Aldrich, 90\%) for the polystyrene sample. Porphyrin samples were run on LDI-TOF (linear) without matrices.

Synthesis of 5,10,15,20-Tetrakis(4-(2-methyl-2-bromopropoxy)phenyl)-21 $\boldsymbol{H}, \mathbf{2 3} \boldsymbol{H}$-porphine (2). 5,10,15,20-Tetrakis(4-hydroxyphenyl)-21H,23H-porphine $\left(400 \mathrm{mg}, 5.9 \times 10^{-4} \mathrm{~mol}\right)$, triethylamine $(1 \mathrm{~mL})$ and dichloromethane $(50 \mathrm{~mL})$ were combined under nitrogen in an ice bath. 2-bromo-2-methylpropionyl bromide $\left(3.2 \mathrm{~g}, 1.4 \times 10^{-2} \mathrm{~mol}\right)$ in anhydrous dichloromethane $(10 \mathrm{~mL})$ was added dropwise over $15 \mathrm{~min}$. The mixture was allowed to warm to room temperature and then stirred for $18 \mathrm{~h}$. The reaction mixture was then washed with $1 \%$ aqueous $\mathrm{NaOH}$ solution, and the organic layer was reduced to a minimum under reduced pressure. The resulting solution was purified by silica flash chromatography (eluent: dichloromethane). After removal of the solvent the porphyrin was isolated as a purple powder.

Yield: $0.68 \mathrm{~g}, 91 \% .{ }^{1} \mathrm{H}$ NMR $\left(\mathrm{CDCl}_{3}, 270 \mathrm{MHz}\right): \delta_{\mathrm{H}} \mathrm{ppm} 2.2$ (s, 24H, C( $\left.\left(\mathrm{CH}_{3}\right)_{2} \mathrm{Br}\right), 7.55(\mathrm{~d}, 8 \mathrm{H}, \mathrm{Ar}-\mathrm{H}), 8.25(\mathrm{~d}, 8 \mathrm{H}, \mathrm{Ar}-\mathrm{H})$,
8.89 (s, 8H, pyrrole-H), 12.2 (br s, $0.7 \mathrm{H}, \mathrm{N}-\mathrm{H}) .{ }^{13} \mathrm{C} \mathrm{NMR}\left(\mathrm{CDCl}_{3}\right.$, $67.9 \mathrm{MHz}): \delta_{\mathrm{C}}$ ppm $170(\mathrm{C}=\mathrm{O}), 151$ ((benzene ring $\left.) \mathrm{C}-\mathrm{O}-\right), 140$ (inner carbon on benzene ring), 135, 131 (ortho- and meta-carbons on benzene ring), 119 (pyrrole rings), $55\left(\mathbf{C}\left(\mathrm{CH}_{3}\right)_{2}\right), 31\left(\mathrm{C}\left(\mathrm{CH}_{3}\right)_{2}\right)$. MALDI-TOF mass spectrometry: $\mathrm{m} / \mathrm{z}, 1271$ 1272, 1273, 1274, $1275,1276,1277,1278,1279$ (isotopic pattern of $\mathrm{M}^{+}(1275)$ ).

Typical ATRP Procedure. 10,15,20-Tetrakis(4-(2-methyl-2bromopropoxy)phenyl)-21H,23H-porphine (2) $\left(50 \mathrm{mg}, 3.9 \times 10^{-5}\right.$ mol), methyl methacrylate $(1.57 \mathrm{~g}, 0.0157 \mathrm{~mol})$, copper(I) bromide $\left(24 \mathrm{mg}, 1.68 \times 10^{-4} \mathrm{~mol}\right), N$-(n-propyl)-2-pyridylmethanimine $(\mathrm{NPPM})\left(52 \mathrm{mg}, 3.51 \times 10^{-4} \mathrm{~mol}\right)$, and toluene $(2 \mathrm{~mL})$ were combined in a Schlenk tube and subjected to three freeze-thaw cycles, then stirred at $90{ }^{\circ} \mathrm{C}$ under nitrogen for $17 \mathrm{~h}$. The reaction mixture was then precipitated by the dropwise addition into hexane $(15 \mathrm{~mL})$. After isolation by filtration the polymer was dissolved in toluene and precipitated by the dropwise addition into a stirred solution of methanol $(15 \mathrm{~mL})$. The polymer was then filtered, dried in a desiccator under vacuum and the structure confirmed by ${ }^{1} \mathrm{H}$ and ${ }^{13} \mathrm{C}$ NMR and the molecular weight parameters analyzed by SEC.

All star polymers were synthesized with porphyrin initiator: monomer molar ratios of 1:400 or 1:800. P8 was synthesized using a 1:1 molar ratio of isobutyl methacrylate to 2,2,2-trifluoroethyl methacrylate.

Where kinetic analyses were performed, similar reactions were carried out as above but samples $(0.1 \mathrm{~mL})$ were taken by syringe at appropriate time intervals. The sample solutions were filtered through short alumina columns which were then rinsed through with $\mathrm{CDCl}_{3}$ and the monomer conversions recorded by ${ }^{1} \mathrm{H} \mathrm{NMR}$ and molecular weight parameters by SEC.

P1 (Porphyrin 2 core PMMA star): ${ }^{1} \mathrm{H}$ NMR $\left(\mathrm{CDCl}_{3}, 270\right.$ $\mathrm{MHz}$ ): $\delta_{\mathrm{H}} \mathrm{ppm} 0.84$ (br s, $-\mathrm{CH}_{3}$ (rr)) 1.02 (br s, $\left.-\mathrm{CH}_{3}(\mathrm{mr})\right) 1.21$ (br s, $\left.-\mathrm{CH}_{3}(\mathrm{~mm})\right) 1.6-2.2\left(-\mathrm{CH}_{2}\right) 3.60\left(\right.$ br s, $\left.-\mathrm{OCH}_{3}\right) 7.47$ (br d, porph $-\mathrm{Ar}-\mathrm{H}$ ) 8.22 (br d, porph-Ar-H) 8.87 (br s, pyrroleH). ${ }^{13} \mathrm{C} \mathrm{NMR}\left(\mathrm{CDCl}_{3}, 67.9 \mathrm{MHz}\right): \delta_{\mathrm{C}} \mathrm{ppm} 16.6\left(-\mathrm{CH}_{3}(\mathrm{rr})\right) 18.8$ $\left(-\mathrm{CH}_{3}(\mathrm{rm})\right) 43-46\left(-\mathrm{CH}_{2}-\mathrm{C}\left(\mathrm{CH}_{3}\right)-\right) 51.7\left(-\mathrm{OCH}_{3}\right) 52.2-55.2$ $\left(-\mathrm{CH}_{2}-\right)$ 176-179 $(\mathrm{C}=\mathrm{O})$.

P5 (Porphyrin 2 core PS star): ${ }^{1} \mathrm{H}$ NMR $\left(\mathrm{CDCl}_{3}, 270 \mathrm{MHz}\right)$ : $\delta_{\mathrm{H}} \mathrm{ppm} 1.0-1.7\left(-\mathrm{CH}_{2}\right)$ 1.7-2.3 $(\mathrm{CH}) 5.9-6.7$ (ortho- $\left.\mathrm{H}\right)$ 6.77.5 (meta- and para-H), 7.50 (br d, porph-Ar-H) 8.22 (br d, porph- $\mathrm{Ar}-\mathrm{H}) 8.84$ (br s, pyrrole- $\mathrm{H}) .{ }^{13} \mathrm{C} \mathrm{NMR}\left(\mathrm{CDCl}_{3}, 67.9\right.$ $\mathrm{MHz}): \delta_{\mathrm{C}}$ ppm $40.4(-\mathrm{CH}-)$ 41.5-46.5 (- $\left.\mathrm{CH}_{2}-\right) 125.5(\mathrm{Ar}$ positions 2, 3, and 4) 143-148 (Ar position 1).

P7 (Porphyrin 2 core PMA star): ${ }^{1} \mathrm{H}$ NMR $\left(\mathrm{CDCl}_{3}, 270 \mathrm{MHz}\right)$ : $\delta_{\mathrm{H}} \mathrm{ppm} 1.2-1.8(-\mathrm{CH}) 1.8-2.6\left(\mathrm{CH}_{2}\right) 7.51(\mathrm{br} \mathrm{d}$, porph $-\mathrm{Ar}-\mathrm{H})$ 8.21 (br d, porph-Ar-H) 8.86 (br s, pyrrole-H). ${ }^{13} \mathrm{C}$ NMR $\left(\mathrm{CDCl}_{3}, 67.9 \mathrm{MHz}\right): \delta_{\mathrm{C}} \mathrm{ppm} 33-38(-\mathrm{CH}-) 41.4\left(-\mathrm{OCH}_{3}\right) 51.6$ $\left(-\mathrm{CH}_{2}-\right) 174.9(\mathrm{C}=\mathrm{O})$.

P8 (Porphyrin 2 core PBMA star): ${ }^{1} \mathrm{H}$ NMR $\left(\mathrm{CDCl}_{3}, 270\right.$ $\mathrm{MHz}): \delta_{\mathrm{H}}$ ppm $0.5-1.1\left(-\mathrm{CH}_{2} \mathrm{CH}_{3}\right.$ and $\left.\mathrm{C}-\mathrm{CH}_{3}\right), 1.40\left(-\mathrm{CH}_{2-}\right.$ $\left.\mathrm{CH}_{3}\right), 1.59\left(-\mathrm{CH}_{2} \mathrm{CH}_{2} \mathrm{CH}_{3}\right), 1.7-2.0\left(-\mathrm{CH}_{2}-\mathrm{C}-\right), 3.94\left(-\mathrm{OCH}_{2}-\right)$. ${ }^{13} \mathrm{C} \mathrm{NMR}\left(\mathrm{CDCl}_{3}, 67.9 \mathrm{MHz}\right): \delta_{\mathrm{C}} \mathrm{ppm} 13.7\left(-\mathrm{CH}_{2} \mathrm{CH}_{3}\right), 16.8$ $\left(-\mathrm{CH}_{2} \mathrm{CH}_{3}\right), 17.7-19.9\left(-\mathrm{C}-\mathrm{CH}_{3}\right), 30.3\left(-\mathrm{CH}_{2} \mathrm{CH}_{2} \mathrm{CH}_{3}\right), 44-$ $46\left(\mathrm{CH}_{2}-\mathrm{C}\left(\mathrm{CH}_{3}\right)-\right), 51-55\left(-\mathrm{CH}_{2}-\mathrm{C}\left(\mathrm{CH}_{3}\right)-\right), 64.7\left(\mathrm{O}-\mathrm{CH}_{2}-\right)$, $176-179(\mathrm{C}=\mathrm{O})$.

P10 (Porphyrin 2 core PIBM-co-PTFM star): ${ }^{1} \mathrm{H}$ NMR $\left(\mathrm{CDCl}_{3}\right.$, $270 \mathrm{MHz}$ ): $\delta_{\mathrm{H}}$ ppm $0.7-1.2$ (backbone- $\mathrm{CH}_{2}$ and $\left.\mathrm{O}-\mathrm{CH}_{2}-\left(\mathrm{CH}_{3}\right)_{2}\right)$ $1.6-2.2\left(\mathrm{C}-\mathrm{CH}_{3}\right) 3.6-3.8\left(\mathrm{CH}_{2}{ }^{\mathrm{I}} \mathrm{Bu}\right) 4.2-4.5\left(\mathrm{CH}_{2}-\mathrm{CF}_{3}\right) .{ }^{13} \mathrm{C}$ $\mathrm{NMR}\left(\mathrm{CDCl}_{3}, 67.9 \mathrm{MHz}\right): \delta_{\mathrm{C}} \mathrm{ppm} 15-20\left(-\mathrm{CH}_{3}\right) 26-28\left(-\mathrm{CH}_{3}\right.$ and $\left.\mathrm{C}\left(\mathrm{CH}_{3}\right)_{2}\right) 43-46\left(-\mathrm{CH}_{2}-\right.$ and $-\mathbf{C}$ - and $\left.-\mathrm{OCH}_{3}\right)$. Ratio of IBMA:TFEMA in $\mathbf{P 9}=1: 1.28$ by ${ }^{1} \mathrm{H}$ NMR.

P11 (Porphyrin 2 core PODA star): ${ }^{1} \mathrm{H}$ NMR $\left(\mathrm{CDCl}_{3}, 270\right.$ $\mathrm{MHz}): \quad \delta_{\mathrm{H}}$ ppm $0.8\left(-\left(\mathrm{CH}_{2}\right)_{n} \mathrm{CH}_{3}, 1.1-1.4\left(-\mathrm{CH}_{2} \mathrm{CH}-\right.\right.$ and $\left.-\left(\mathrm{CH}_{2}\right)_{n}-\right), 1.5-1.7\left(-\mathrm{OCH}_{2} \mathrm{CH}_{2}\right), 3.9-4.1\left(-\mathrm{O}-\mathrm{CH}_{2}-\right)$.

Metalation of 10,15,20-Tetrakis(4-(2-methyl-2-bromopropoxy)phenyl)-21H,23H-porphine (2). The relevant metal salt $\left(\mathrm{CuBr}_{2}\right.$, or $\mathrm{PdCl}_{2}$ ) (5 molar equiv) and $\mathbf{2}$ (1 molar equiv) were combined under nitrogen in a 1:1 mixture of dichloromethane and methanol $(50 \mathrm{~mL})$. The mixture was brought to reflux for $12 \mathrm{~h}$ and cooled. The solvent was reduced to a minimum under reduced pressure. 
Table 1. Reaction Conditions, Molecular Weight Parameters and Monomer Conversions of the Star Polymers Made by ATRP Polymerization from Porphyrin Initiators 2 and 4

\begin{tabular}{|c|c|c|c|c|c|c|c|c|}
\hline polymer & initiator & solvent & monomer & $\operatorname{ligand}^{a}$ & $M_{\mathrm{n}, \text { theor }}{ }^{b}$ & $M_{\mathrm{n}}^{c}$ & $M_{\mathrm{w}} / M_{\mathrm{n}}$ & $\operatorname{convn}^{e}(\%)$ \\
\hline P1 & free base (2) & toluene & MMA & NPPM & 39250 & $41350^{d}$ & 1.21 & 98 \\
\hline P2 & free base (2) & toluene & MMA & NPPM & 35240 & 32040 & 1.27 & 88 \\
\hline P3 & zinc (4) & toluene & MMA & NPPM & 30840 & 29450 & 1.25 & 77 \\
\hline P4 & free base (2) & toluene & styrene & bipyridyl & 16744 & 34640 & 1.87 & 39 \\
\hline P5 & free base (2) & anisole & styrene & PMEDTA & 28730 & 23440 & 1.37 & 33 \\
\hline P6 & free base (2) & anisole & styrene & PMEDTA & 23180 & 22980 & 1.26 & 54 \\
\hline P7 & free base (2) & anisole & MA & NPPM & 18930 & 15660 & 1.28 & 53 \\
\hline P8 & free base (2) & none & BMA & NPPM & 34890 & 118240 & 1.27 & 60 \\
\hline P9 & free base (2) & anisole & BMA & NPPM & 29660 & 46000 & 1.94 & 51 \\
\hline P10 & free base (2) & toluene & IBMA/TFEMA & NPPM & 26600 & 17755 & 1.30 & 42 \\
\hline P11 & free base (2) & toluene & ODA & NOPM & 48500 & 48030 & 1.36 & 37 \\
\hline $\mathrm{P} 12$ & zinc (4) & toluene & IBMA/TFEMA & NPPM & 43070 & 30000 & 1.64 & 68 \\
\hline
\end{tabular}

${ }^{a} \mathrm{NPPM}=N$-(n-propyl)-2-pyridylmethanimine; PMEDTA $=1,1,4,7,7$-pentamethyldiethylenetriamine; NOPM $=N$ - $(n$-octyl)-2-pyridylmethanimine; bipyridyl $=2,2^{\prime}$-bipyridine. ${ }^{b}$ From $\left\{[\mathrm{M}]_{0} / 4[\mathrm{I}]_{0}\right\} \times(\%$ conversion $) \times\left(M_{\mathrm{r}}\right.$ monomer $) .{ }^{c}$ SEC. ${ }^{d} M_{\mathrm{n}}=41040$ and $M_{w} / M_{\mathrm{n}}=1.11$ from MALDI-TOF.

Table 2. $\lambda_{\max }$ of the Q-Bands above for Free-Base and Metalated Samples and Porphyrin-Core Star Polymers $\left(\mathrm{CH}_{2} \mathrm{Cl}_{2}, 0.1 \mathrm{~g} \mathrm{dm}^{-3}\right)$

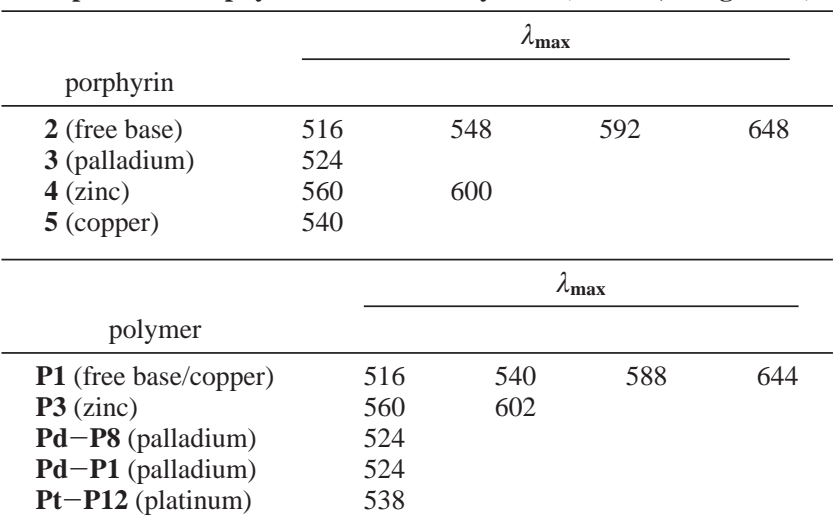

The resulting solution was purified by silica flash chromatography (eluent dichloromethane:methanol, 100:1).

A similar procedure was followed for the complexation of $\mathrm{Zn}$ using $\mathrm{ZnBr}_{2}$ (5 molar equiv) but 1,4-diazabicyclo[2.2.2] octane (1.2 molar equiv) was also added at the start of the reaction.

Palladium (3): Orange powder, yield $=0.079 \mathrm{~g}, 56 \% .{ }^{1} \mathrm{H}$ NMR $\left(\mathrm{CDCl}_{3}, 270 \mathrm{MHz}\right): \delta_{\mathrm{H}} \mathrm{ppm} 2.23\left(\mathrm{~s}, 24 \mathrm{H}, \mathrm{C}\left(\mathrm{CH}_{3}\right)_{2} \mathrm{Br}\right), 7.54(\mathrm{~d}$, $8 \mathrm{H}, \mathrm{Ar}-\mathrm{H}), 8.21(\mathrm{~d}, 8 \mathrm{H}, \mathrm{Ar}-\mathrm{H}), 8.83(\mathrm{~s}, 8 \mathrm{H}$, pyrrole- $\mathrm{H}){ }^{13} \mathrm{C} \mathrm{NMR}$ $\left(\mathrm{CDCl}_{3}, 67.9 \mathrm{MHz}\right): \delta_{\mathrm{C}} \mathrm{ppm} 30.8\left(-\mathrm{C}\left(\mathrm{CH}_{3}\right)_{2}-\right), 55.5\left(-\mathbf{C}\left(\mathrm{CH}_{3}\right)_{2}-\right)$, 119.5 ( $\beta$-pyrrole), 120.8 ( $\alpha$-pyrrole), 131.1 (aromatic $-\mathrm{O}-\mathrm{C}-$ $\mathbf{C H}-$ ), 134.9 (aromatic $-\mathrm{O}-\mathrm{C}-\mathrm{CH}-\mathrm{CH}-$ ), $139.5(-\mathrm{O}-\mathrm{C}-$ aromatic) (LDI-TOF mass spectrometry $\left[\mathrm{M}^{+}\right]=1379$ (the chromatogram and isotopic pattern is given in the Supporting Information).

Zinc (4): Pink powder, yield $=0.117 \mathrm{~g}, 56 \% .{ }^{1} \mathrm{H} \mathrm{NMR}\left(\mathrm{CDCl}_{3}\right.$, $270 \mathrm{MHz}): \delta_{\mathrm{H}} \mathrm{ppm} 2.23\left(\mathrm{~s}, 24 \mathrm{H}, \mathrm{C}\left(\mathrm{CH}_{3}\right)_{2} \mathrm{Br}\right), 7.56(\mathrm{~d}, 8 \mathrm{H}, \mathrm{Ar}-$ $\mathrm{H}), 8.25(\mathrm{~d}, 8 \mathrm{H} \mathrm{Ar}-\mathrm{H}), 8.92(\mathrm{~s}, 8 \mathrm{H}$, pyrrole-H).

Copper (5): Dark red powder, yield $=0.052 \mathrm{~g}, 51 \% .{ }^{1} \mathrm{H}$ NMR $\left(\mathrm{CDCl}_{3}, 270 \mathrm{MHz}\right): \delta_{\mathrm{H}}$ ppm $2.23\left(\mathrm{~s}, 24 \mathrm{H}, \mathrm{C}\left(\mathrm{CH}_{3}\right)_{2} \mathrm{Br}\right), 7.53(\mathrm{~d}$, $8 \mathrm{H}, \mathrm{Ar}-\mathrm{H}), 8.22(\mathrm{~d}, 8 \mathrm{H}, \mathrm{Ar}-\mathrm{H}), 8.94(\mathrm{~s}, 8 \mathrm{H}$, pyrrole- $\mathrm{H})$.

$\mathrm{UV} / \mathrm{vis}$ absoption data can be found in Table 2.

Metalation of Polymers. A solution of P1 $(1.50 \mathrm{~g})$ and $\mathrm{PdCl}_{2}$ $(0.10 \mathrm{~g})$ in DMF $(10 \mathrm{~mL})$ was stirred and heated at $110{ }^{\circ} \mathrm{C}$ for 7 days. The palladium-containing polymer $(\mathbf{P 1}-\mathbf{P d})$ was then precipitated from solution by addition to excess water, filtered, dissolved in dichloromethane and then precipitated from excess methanol to give an orange-brown powder in a $65 \%$ yield. The nature of the chromophore was investigated by UV-visible spectroscopy (see Figure 2), and fluorescence spectroscopy (see Figure 7).

The zinc-metalated polymer $\mathbf{P 3}$ was trans-metalated in a similar manner (by heating a solution of $\mathbf{P 3}$ and $\mathrm{PdCl}_{2}$ in DMF to $110{ }^{\circ} \mathrm{C}$ for 7 days) to give $\mathbf{P 3}-\mathbf{P d}$ as an orange-brown powder in a $65 \%$ yield.

A solution of P12 (1.44 g) and $\mathrm{PtCl}_{2}(0.012 \mathrm{~g})$ in benzonitrile $(10 \mathrm{~mL})$ was stirred and heated under reflux conditions for 7 days.
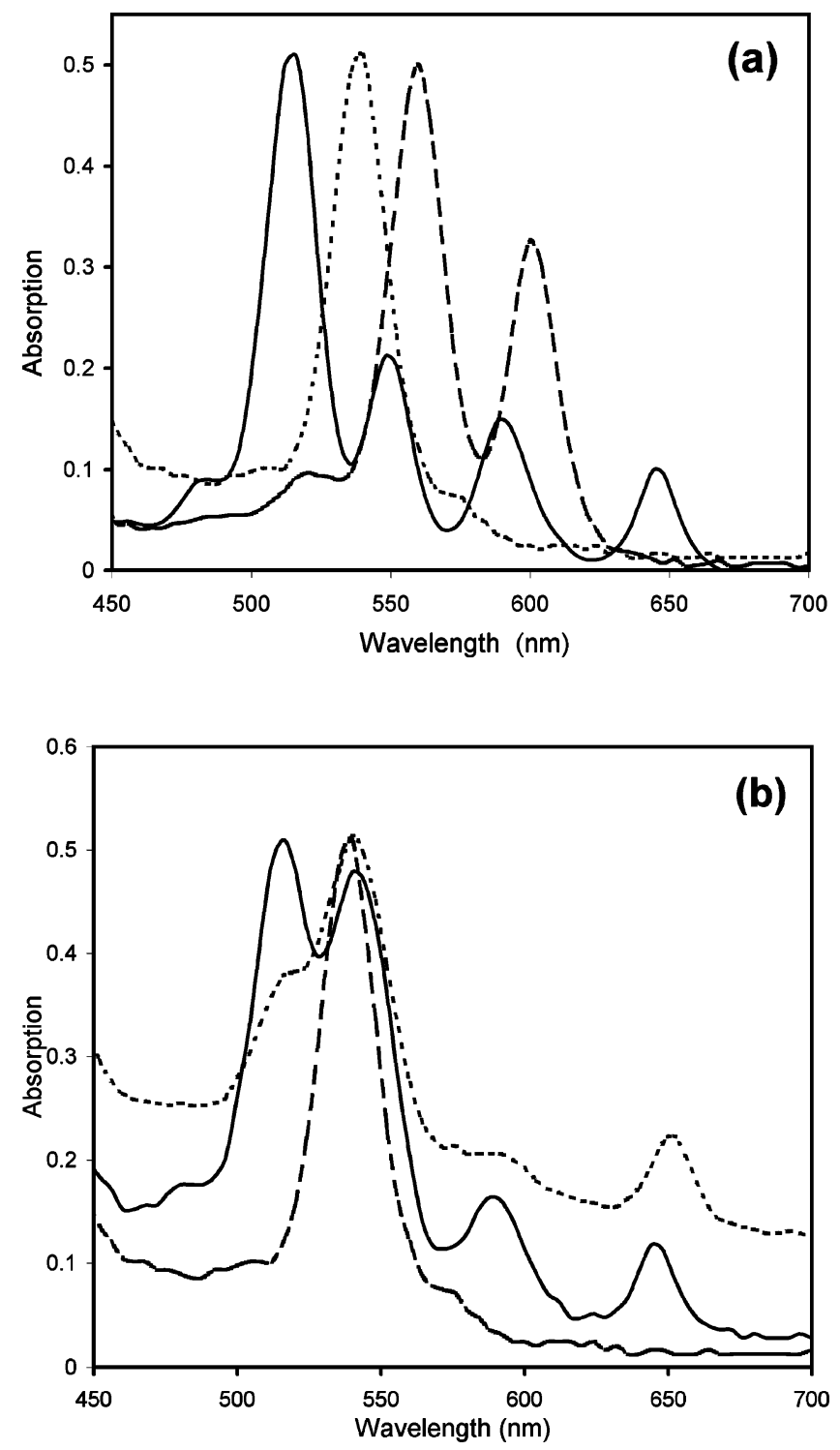

Figure 1. Visible spectra illustrating the $\mathrm{Q}$ bands of the (a) free-base (2) (-), Pd (3) (․) and Zn (4) (---) tetrabromoporphyrins; (b) porphyrin-core star polymers of MMA $(\mathbf{P 1}),(-)$, styrene $(\mathbf{P 4})(\cdots)$ and the $\mathrm{Cu}(\mathrm{II})$ tetrabromoporphyrin $(\mathbf{5})(---)$.

The mixture was then diluted with dicholoromethane and the platinum-containing polymer $(\mathbf{P t}-\mathbf{P 1 2})$ was then precipitated from excess hexane, filtered and then dissolved in dicholoromethane and precipitated from excess methanol to give an red-brown powder in a $65 \%$ yield. The nature of the chromophore was investigated by 

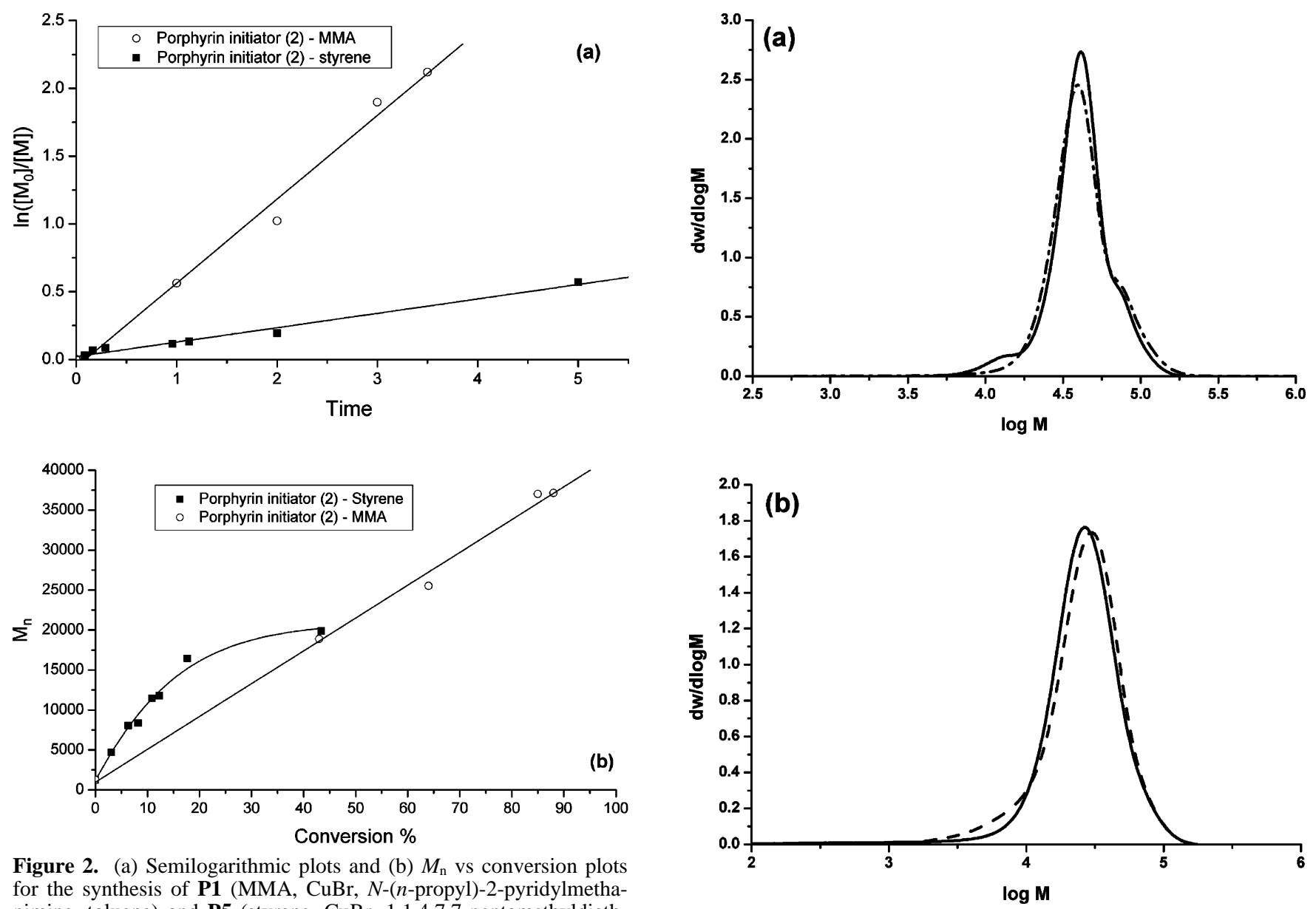

Figure 2. (a) Semilogarithmic plots and (b) $M_{\mathrm{n}}$ vs conversion plots for the synthesis of P1 (MMA, CuBr, $N$-(n-propyl)-2-pyridylmethanimine, toluene) and $\mathbf{P 5}$ (styrene, $\mathrm{CuBr}, 1,1,4,7,7$-pentamethyldiethylenetriamine, anisole).

UV-visible spectroscopy (Supporting Information) and fluorescence spectroscopy (see Figure 7b).

Hydrolysis of Ester Linker in Porphyrin-Core Polystyrene Star (P4). A solution of P4 (0.05 g), KOH (10 g), and 15-crown-5 (1 drop) in THF/water/ethanol $(5 \mathrm{~mL} / 0.5 \mathrm{~mL} / 0.2 \mathrm{~mL})$ was stirred and heated under reflux conditions for $16 \mathrm{~h}$. After cooling, the solution mixture was added to an excess of methanol $(\sim 40 \mathrm{~mL})$, redissolved in THF, and precipitated from an excess of ethanol. The precipitate was rinsed with water/ethanol and then ethanol and then dried. The very lightly colored (creamy brown) powder was then analyzed by SEC using UV-vis and RI detectors.

Before hydrolysis P4: $M_{\mathrm{n}}=23,440, M_{\mathrm{w}}=32100, M_{\mathrm{w}} / M_{\mathrm{n}}=$ $1.37(\mathrm{RI}) ; M_{\mathrm{n}}=24,200, M_{\mathrm{w}}=31560, M_{\mathrm{w}} / M_{\mathrm{n}}=1.25(400 \mathrm{~nm})$.

After hydrolysis P4: $M_{\mathrm{n}}=5,290, M_{\mathrm{w}}=6,070, M_{\mathrm{w}} / M_{\mathrm{n}}=1.15$ $(\mathrm{RI}) ; M_{\mathrm{n}}=5,060, M_{\mathrm{w}}=5,980, M_{\mathrm{w}} / M_{\mathrm{n}}=1.18(254 \mathrm{~nm})$.

Fluorescent Film Formulations. Two polymer solutions for casting as thin fluorescent films were made up as follows. Solution A: $0.015 \mathrm{~g}$ of Pd-P1 (1 wt \% of total film weight) was mixed with $10 \mathrm{~mL}$ of a $15 \%(\mathrm{w} / \mathrm{v})$ stock solution of poly(butyl methacrylate)-co-(methyl methacrylate) in butyl acetate. Solution B: 0.01 $\mathrm{g}$ of Pd-P8 (1 wt \% of total film weight) was mixed with $10 \mathrm{~mL}$ of a $10 \%(\mathrm{w} / \mathrm{v})$ stock solution of poly(isobutyl methacrylate)-co(trifluoroethyl methacrylate) in butyl acetate.

The solutions were cast using an artist's airbrush onto quartz slides (AGAR scientific) connected to the laboratory compressed air supply. The application was deliberately not quantitative, but the thicknesses were measured (using a handheld micrometer) to be between 14 and $26 \mu \mathrm{m}$.

\section{Results}

Synthesis of Porphyrin ATRP Initiators. The free-base porphyrin initiator (2) was synthesized by the esterification of 5,10,15,20-tetrakis(4-hydroxyphenyl)-21H, 23H-porphine (1)

Figure 3. Overlay of molecular weight distribution plots obtained by SEC illustrating distribution measured by UV-vis detector $(400 \mathrm{~nm}$, dashed line) and RI detector (solid line) of (a) star polymer P1 and (b) star polymer $\mathbf{P 4}$.

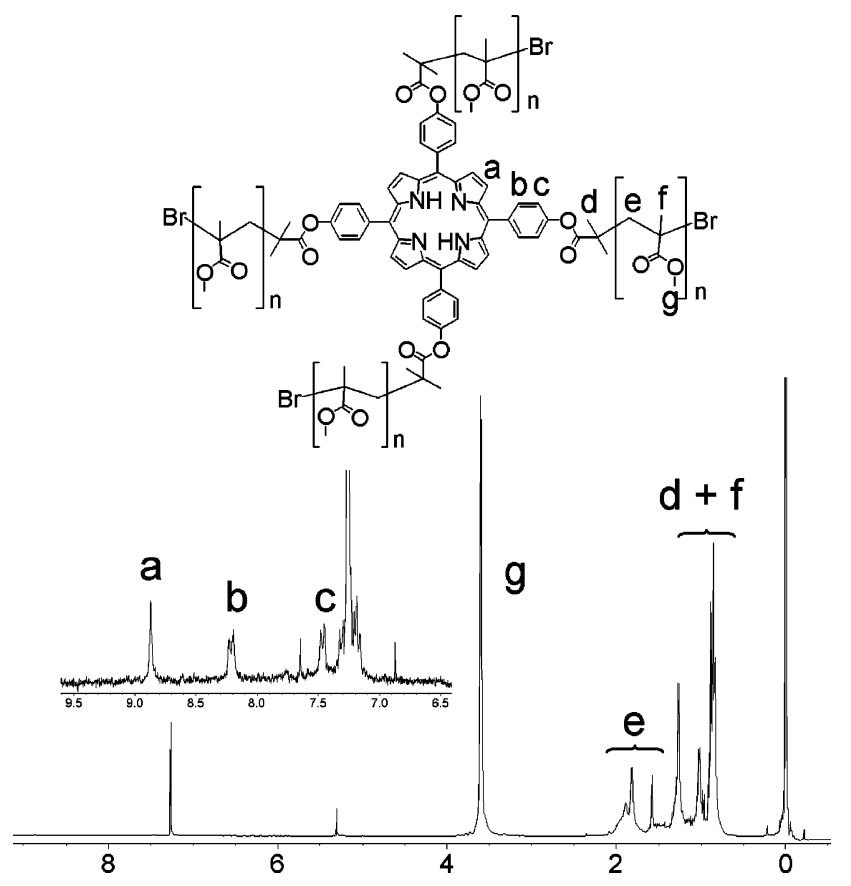

Figure 4. ${ }^{1} \mathrm{H}$ NMR spectrum of P1. Expansion shows resonances attributed to the porphyrin core. Resonance centered at $7.26 \mathrm{ppm}$ due to a trace of $\mathrm{CHCl}_{3}$ and residual toluene.

with 2-bromo-2-methylpropanoyl bromide in the presence of triethylamine (Scheme 1). ${ }^{11}$ During the reaction competition 


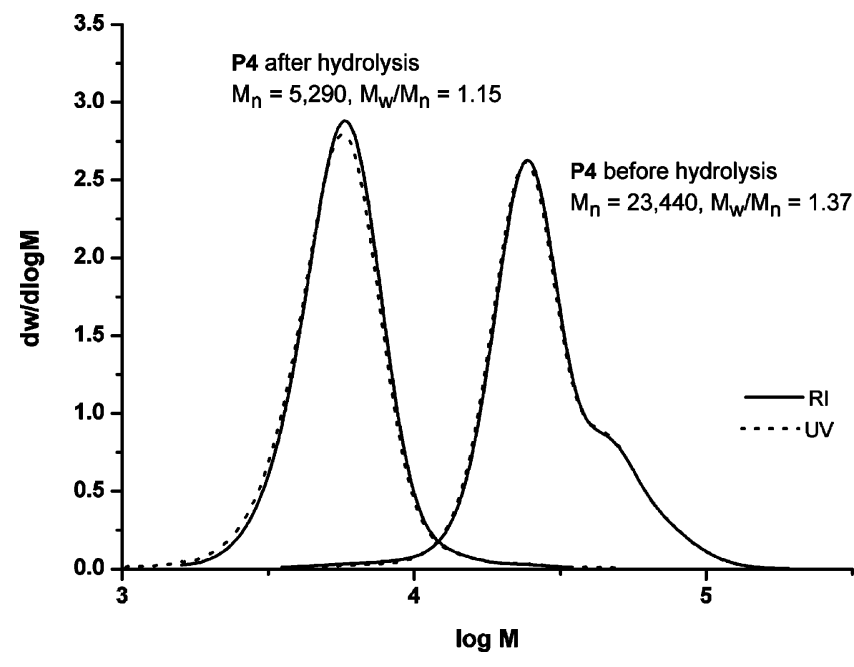

Figure 5. Overlay of molecular weight distribution plots obtained by SEC for $\mathbf{P 4}$ before and after basic hydrolysis illustrating distribution measured by UV-vis detector (solid line, $400 \mathrm{~nm}$ for prehydrolysis, $254 \mathrm{~nm}$ posthydrolysis) and RI detector (dashed line).

between the porphyrin and triethylamine for the $\mathrm{HBr}$ liberated during esterification meant that a wash of the product solution with dilute aqueous $\mathrm{NaOH}$ was necessary to neutralize significant quantities of protonated porphyrin (characterized by a green color). Subsequent to this wash and further purification by column chromatography, the neutral porphyrin (characterized by a purple color) was obtained in high yields (91\%). It would appear likely that the low yield $(21 \%)$ recorded by Beil and Zimmerman for the synthesis of a similar porphyrin was result of retention of the protonated porphyrin on the column. ${ }^{9 b}$

The successful metalation of the free-base tetrabromoporphyrin (2) was performed by heating the compound with the relevant metal salts $\left(\mathrm{ZnBr}_{2}, \mathrm{CuBr}_{2}\right.$, or $\left.\mathrm{PdCl}_{2}\right)$ in dichloromethane/methanol mixed solvent under reflux conditions. ${ }^{12}$ Whereas the $\mathrm{Pd}$ and $\mathrm{Cu}$ porphyrins were obtained in reasonable yields ( $>50 \%$ ) following this method the $\mathrm{Zn}$ complexation led to yields of less than $10 \%$ of the desired complex. Analysis of the byproducts indicated that cleavage of the ester functions was taking place in the presence of $\mathrm{Zn}$ and liberated $\mathrm{HBr}$ and consequently 1,4-diazbicyclo[2.2.2]octane was employed as a base in the reaction whereupon yields of $50 \%$ were obtained. The resultant metal porphyrin complexes were characterized by ${ }^{1} \mathrm{H}$ NMR spectroscopy, MALDI-TOF and UV-vis spectroscopy. The UV-vis spectra of these complexes accorded with those observed for similar porphyrin metal complexes (Figure 1a,b). ${ }^{13}$

ATRP from Porphyrin Initiators. The tetrabromo-Pdporphyrin (3) was employed as the initiator for the subsequent attempted polymerization of styrene employing various ATRP catalysts ( $N$-( $n$-propyl)-2-pyridylmethanimine, 2,2-bipyridine, PMEDTA) and conditions (toluene, bulk, $80-110^{\circ} \mathrm{C}$ ); however, no polymerization of the monomer was observed. ${ }^{14}$

In contrast the polymerization of methyl methacrylate employing the free-base tetrabromoporphyrin (2) as the initiator with $\mathrm{Cu}^{\mathrm{I}} \mathrm{Br} / N$-(n-propyl)-2-pyridylmethanimine (NPPM) as the catalyst system in toluene at $90{ }^{\circ} \mathrm{C}$ proceeded successfully albeit slowly (P1 and P2, Table 1). After 5 days the reactions yielded star polymers of close-to-expected molecular weight parameters, low polydispersities $(<1.3)$ and high conversions $(77-98 \%)$. The polymerization of styrene was attempted employing tetrabromoporphyrin (2) as the initiator using various catalyst systems $\left(\mathrm{Cu}^{\mathrm{I}} \mathrm{Br}, \mathrm{Cu}{ }^{\mathrm{I}} \mathrm{Cl}\right.$, NPPM, 2,2'-bipyridyl) and temperatures $\left(90-110^{\circ} \mathrm{C}\right)$ in toluene and without solvent. With the exception
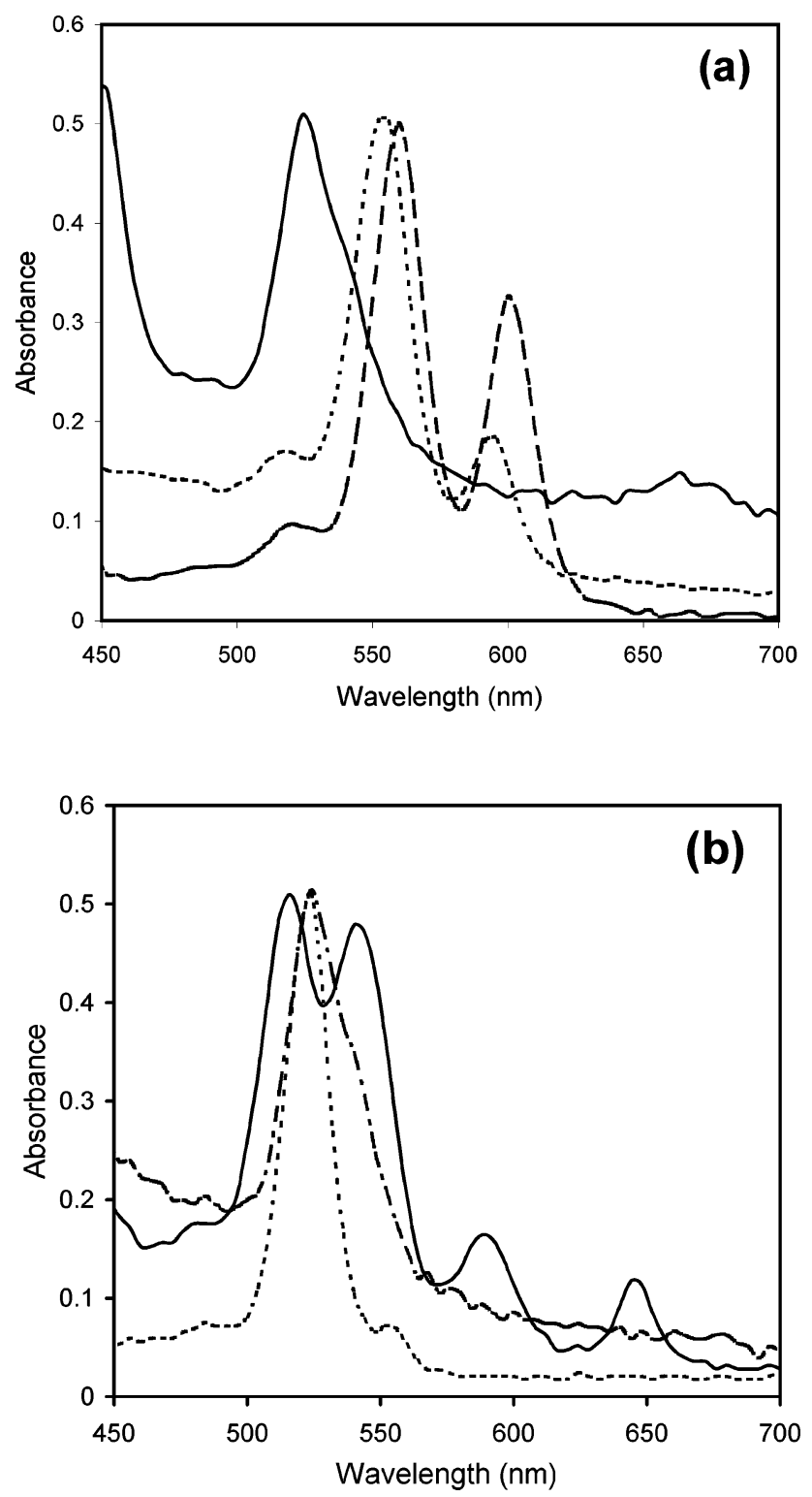

Figure 6. Visible spectra: (a) the $\mathrm{Zn}(\mathrm{II})$ porphyrin-core star-PMMA (P3) ( $\cdots)$, the $\mathrm{Zn}(\mathrm{II})$ (4) tetrabromoporphyrin (---), and the $\mathrm{Pd}(\mathrm{II})$ porphyrin-core star-PMMA (P3-Pd) (-); (b) the Cu(II)/free-base porphyrin-core star-PMMA (P1) $(-)$, the $\mathrm{Pd}(\mathrm{II})$ tetrabromoporphyrin (3) $(\cdots)$, and the resulting $\mathrm{Pd}(\mathrm{II})$ porphyrin-core star-PMMA (P1-Pd) $(--)$.

of the 2,2'-bipyridyl reaction (P4, Table 1$)$ in all other cases no polymeric product resulted. The reaction using the $2,2^{\prime}$-bipyridyl ligand gave a high polydispersity polymer of double the expected molecular weight. Relatively successful polymerizations of styrene resulted upon employing PMEDTA as the ligand for $\mathrm{Cu}^{\mathrm{I}} \mathrm{Br}$ in anisole as the solvent at $90{ }^{\circ} \mathrm{C}$. As with the polymerization of MMA the polymerization was slow and after 5 days however monomer conversions were no higher than $55 \%$. Kinetic analysis of the MMA and styrene polymerizations demonstrated that whereas both polymerizations followed first order behavior (Figure 2a), the number-average molecular weight of the styrene was only linear with monomer conversion up to about $20 \%$. This correlated with almost complete cessation of polymerization. It is likely that the prolonged reaction times employed led to degradation of the $\mathrm{PS}-\mathrm{Br}$ end group (such as by expulsion of $\mathrm{HBr}$ ). Such degradation has previously been observed by other researchers. ${ }^{15}$ The activity of the styrene chain-ends is currently under investigation. One possible reason for the polymerization of MMA, but not styrene, in toluene was 

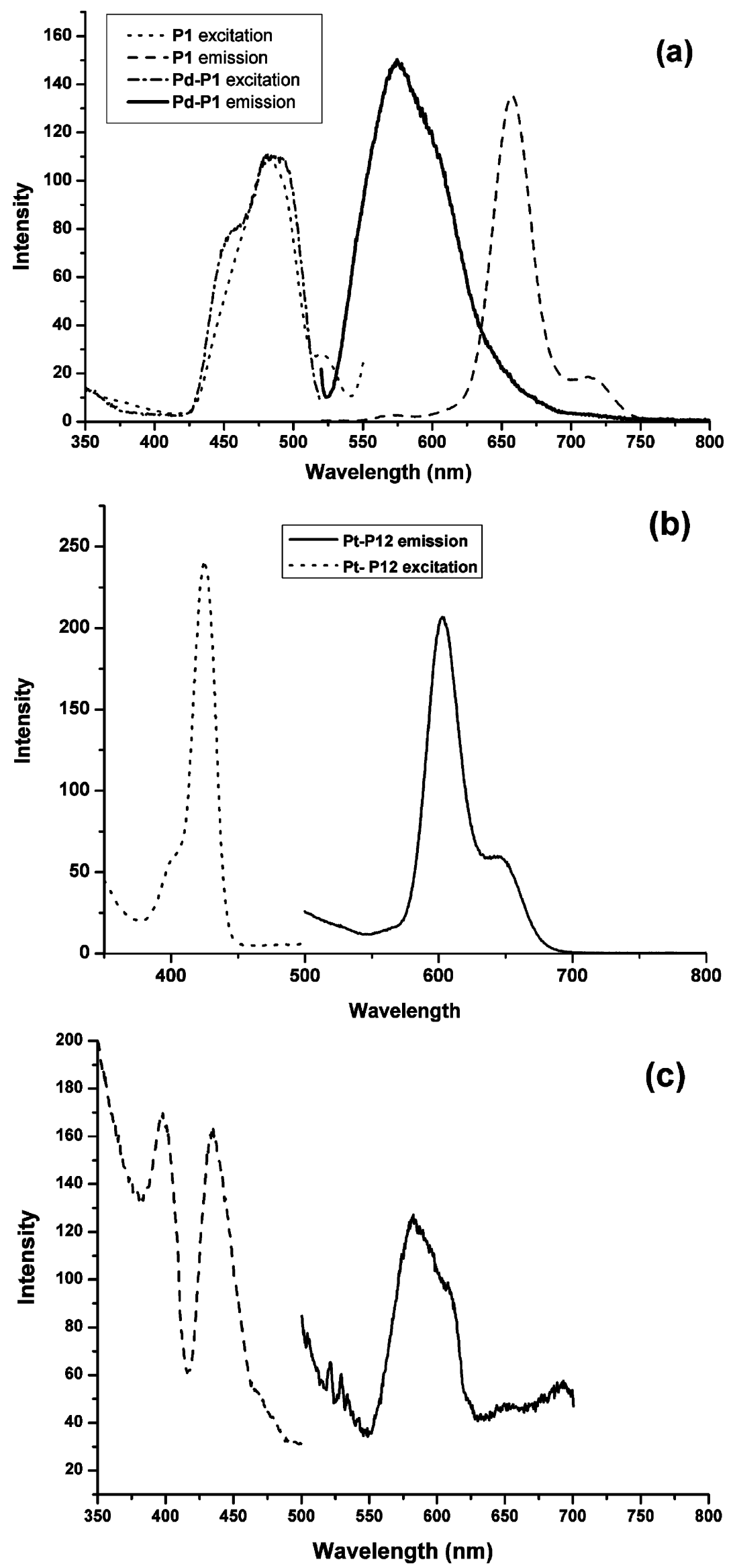

Figure 7. Emission and excitation spectra for (a) the $\mathrm{Cu}(\mathrm{II}) /$ free-base porphyrin-core star-PMMA (P1) and Pd(II) porphyrin-core star-PMMA (P1-Pd) in THF solutions and (b) a film of poly(isobutyl methacrylate)-co-(trifluoroethyl methacrylate) containing 1 wt $\%$ P1-Pd: excitation spectrum $(-)\left(\lambda_{\mathrm{em}} 607 \mathrm{~nm}\right)$ and emission spectrum $(---)\left(\lambda_{\mathrm{exc}} 404 \mathrm{~nm}\right)$. 
Scheme 1. Synthesis of the Tetrabromoporphyrin ATRP Initiator and Metal Complexed Porphyrins

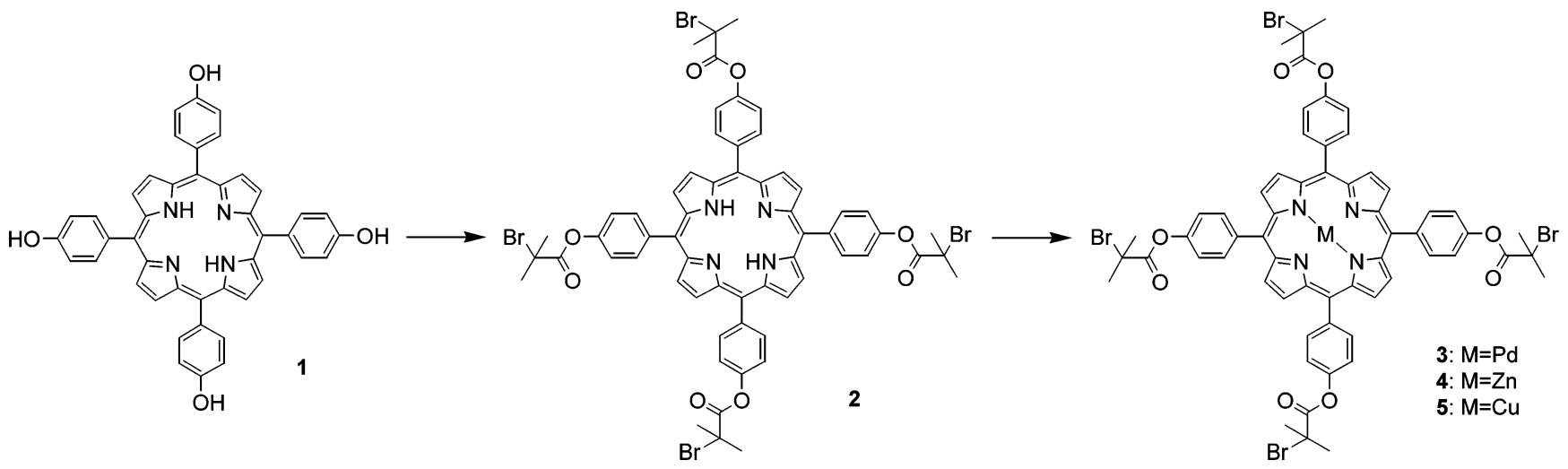

Scheme 2. Synthesis of Star Porphyrin-Core Star PMMA and Metalation of Resultant Polymers
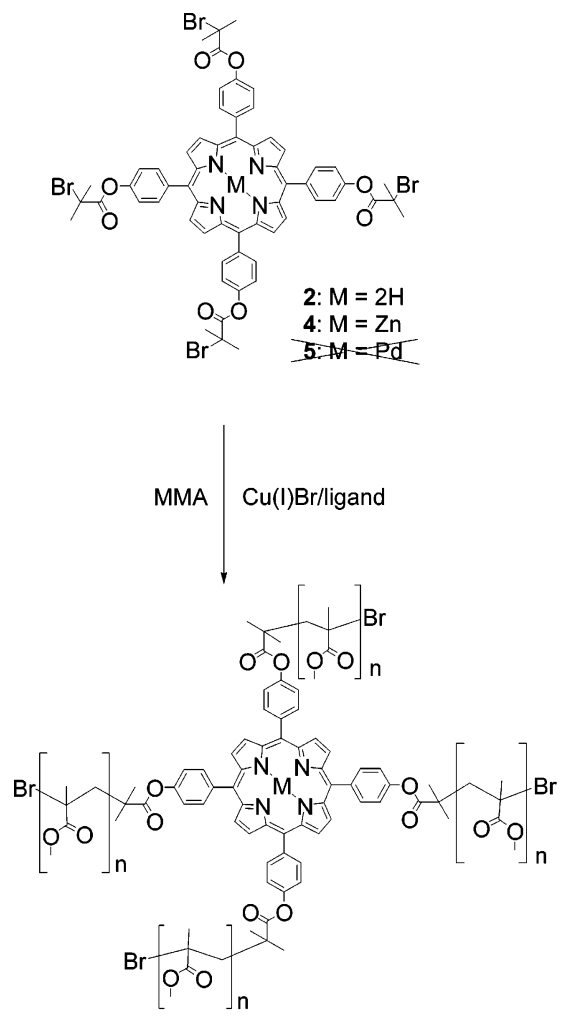

$$
\left.\begin{array}{l}
\text { 6: } M=2 \mathrm{H} / \mathrm{Cu} \\
\text { 7: } \mathrm{M}=\mathrm{Zn}
\end{array}\right\} \frac{\mathrm{PdCl}_{2}}{\mathrm{DMF}, \Delta, \mathrm{N}_{2}} \quad \text { 8: } \mathrm{M}=\mathrm{Pd}
$$

Scheme 3. Monomers Employed in ATRP Using Porphyrin Initiators<smiles>C=Cc1ccccc1</smiles><smiles>C=C(C)C(=O)OC</smiles><smiles>C=CC(=O)OC</smiles>

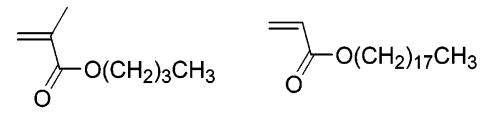<smiles>C=C(C)C(=O)OCC(C)C</smiles><smiles>C=C(C)C(=O)OCC(F)(F)F</smiles>

the reduced solubility of the porphyrin initiator in nonpolar solvents. The mixtures for the MMA polymerizations appeared homogeneous whereas those for the toluene-based styrene polymerizations were inhomogeneous (small particulates were visible). Presumably MMA acts as a cosolvent for the porphyrin initiator whereas in styrene/toluene mixtures solubility is reduced and anisole acts as the polar cosolvent in the styrene polymerizations allowing for the solubilization of the initiator.

It was evident that a degree of metalation of the porphyrin core by copper(II) occurred during the polymerizations as evidenced by comparison of the UV-vis absorption spectra of the free-base porphyrin (2), a $\mathrm{Cu}$ (II) tetrabromoporphyrin (4) and the star polymers (an example of the overlaid UV-vis spectra is shown in Figure 1b). Incorporation of $\mathrm{Cu}(\mathrm{II})$ into a monofunctional initiator porphyrin during ATRP has previously been observed by de Loos et al. ${ }^{9 a}$ All polymers clearly displayed two Q bands with $\lambda_{\max }$ above $450 \mathrm{~nm}$ that were attributable to the free-base porphyrin and a $\mathrm{Cu}(\mathrm{II})$ porphyrin complex respectively. Despite this, the polymeric products were of low polydispersity and close to expected molecular weights for both methyl methacrylate and styrene polymerizations. Size exclusion chromatographic analysis (SEC) of the star polymers was performed using both refractive index and UV absorption detectors; the latter absorption set to $400 \mathrm{~nm}$ (the Soret absorption band characteristic of the porphyrin initiator) and demonstrated the complete incorporation of the porphyrin in the polymers P1 (MMA) and P4 (styrene) (Figure 3). A small quantity of high molecular weight material was evident from the SEC trace of P1 (PMMA) with a peak molecular weight approximately twice that of the $M_{\mathrm{n}}$ of the sample $\left(M_{\mathrm{p}}=\right.$ $\sim 87000$ vs $M_{\mathrm{p}}=\sim 42000$ ). This high molecular weight material was evident in the early stages of the polymerization, and it is likely that it results from a small degree of bimolecular termination during the buildup of excess $\mathrm{Cu}^{\mathrm{II}} \mathrm{Br}_{2}$ (the persistent radical effect). ${ }^{16}$ It is likely that this bimolecular termination could be greatly reduced in future polymerizations by the introduction of $\mathrm{Cu}^{\mathrm{II}} \mathrm{Br}_{2}$ to the initial reaction mixture. MALDITOF analysis of P1 using a trans-indole acrylic acid matrix confirmed the accuracy of the SEC data giving an $M_{\mathrm{n}}$ of 41043 and a polydispersity index of $1.11\left(M_{\mathrm{n}}=41350, M_{\mathrm{w}} / M_{\mathrm{n}}=\right.$ 1.21 by SEC) (chromatogram given in Supporting Information).

Unfortunately ${ }^{1} \mathrm{H}$ NMR analysis of the star polymers would not allow for calculations of molecular weights via end group analysis (a typical NMR spectrum, that of $\boldsymbol{P} \mathbf{1}$ is shown in Figure 4). While the generally good agreement between the theoretical $M_{\mathrm{n}}$ values with measured $M_{\mathrm{n}}$ values provides an indication of efficient initiation and controlled polymerizations, independent confirmation was desired. To confirm that efficient initiation was occurring from the porphyrin core a simple hydrolysis experiment was carried out on a core-porphyrin star-polystyrene (P5) using $\mathrm{KOH}$. After hydrolysis and cleavage of the ester bonds linking the polystyrene chains to the porphyrin core, the $M_{\mathrm{n}}$ value of the remaining PS chains $\left(M_{\mathrm{n}}=5290\right.$ by RI detector) were approximately one-fourth of the initial value $\left(M_{\mathrm{n}}=23440\right)$ 
with a polydispersity index of 1.15 , indicating efficient initiation from the majority of $\mathrm{Br}$ initiating functionalities (Figure 5).

An attempt was made to polymerize methyl acrylate employing the free-base tetrabromoporphyrin (2) as the initiator with $\mathrm{Cu}^{\mathrm{I}} \mathrm{Br} / \mathrm{N}$-(n-propyl)-2-pyridylmethanimine (NPPM) as the catalyst system in toluene at $90{ }^{\circ} \mathrm{C}$. However after $18 \mathrm{~h}$ no polymerization was observed to have occurred. Again it was presumed that the porphyrin initiator was not sufficiently soluble in the reaction mixture to allow initiation to occur, though this was not apparent from simple inspection. A subsequent attempt to polymerize MA in bulk using PMEDTA as the ligand led to an insoluble (presumably cross-linked) material within $2 \mathrm{~h}$. A successful polymerization was obtained by employing the $\mathrm{Cu}^{\mathrm{I}}$ $\mathrm{Br} / N$-(n-propyl)-2-pyridylmethanimine (NPPM) in anisole and the reaction was stopped after $47 \mathrm{~h}$ when the reaction mixture became too viscous for stirring to continue. A low polydispersity polymer $\left(\mathbf{P} 7, M_{\mathrm{w}} / M_{\mathrm{n}}=1.28\right)$ was obtained with $87 \%$ conversion by NMR and with a close to theoretical $M_{\mathrm{n}}$ value by SEC.

Butyl methacrylate similarly did not polymerize using $\mathrm{Cu}^{\mathrm{I}-}$ $\mathrm{Br} / N$-(n-propyl)-2-pyridylmethanimine (NPPM) as the catalyst system in toluene at $90^{\circ} \mathrm{C}$, consequently a bulk polymerization was performed using the same system at $90^{\circ} \mathrm{C}$. After $3 \mathrm{~h}$ the reaction mixture ceased stirring efficiently and subsequent workup gave a polymer (P8) in a $60 \%$ yield (gravimetric). However a substantial discrepancy was observed between the $M_{\mathrm{n}}$ expected for the product of the butyl acrylate polymerization and that observed. Given the size of the differences it would seem unlikely that variance between the hydrodynamic volumes of the standards employed in the SEC calibration (PMMA standards) and butyl methacrylate can account for this discrepancy. No explanation is available at this time however one possibility is that there is poor initiation efficiency of the porphyrin in the bulk mixture (i.e., the rate of propagation exceeds the rate of initiation in the early part of the polymerization). When the polymerization was carried out in anisole a polymer (P9) with an $M_{\mathrm{n}}$ value closer to that predicted was obtained but the polydispersity index was above that expected from a controlled polymerization $\left(M_{\mathrm{w}} / M_{\mathrm{n}}=1.94\right)$. We have previously described the optimized synthesis of poly(octadecyl acrylate) using a $N$-(n-octyl)-2-pyridylmethanimine $/ \mathrm{Cu}{ }^{\mathrm{I}} \mathrm{Br}$ catalyst system, and when a polymerization of octadecyl acrylate in xylene was performed using the free-base tetrabromoporphyrin (2), the reaction was stopped after $76 \mathrm{~h}$, giving a coreporphyrin star-PODA (P11) in 37\%. ${ }^{10 \mathrm{~b}}$ The polymerization of ODA has been previously observed to be slow, and it is likely that the polymerization was incomplete rather than it had ceased.

It has been observed that for optimum performance as oxygen and pressure sensors porphyrins need to be encapsulated in a highly oxygen permeable matrix and the best examples of such polymers to date are silicone-based elastomers or fluorinated (meth)acrylates. ${ }^{17}$ Poly(isobutyl methacrylate-co-trifluoroethyl methacrylate) (PIBMA-co-TFEM) has been observed to act as an efficient $\mathrm{O}_{2}$ permeablepolymer matrix of porphyrins, and consequently, the free-base porphyrin (2) was used as the initiator in the copolymerization by ATRP of isobutyl methacrylate and trifluorethyl methacrylate. ${ }^{18}$ This copolymerization yielded a star copolymer of PIBMA-co-TFEM (44\% IBMA to $56 \%$ TFEMA by monomer incorporation) demonstrating the versatility of the method described for synthesizing covalently bound porphyrin metallopolymers potentially suitable for oxygensensing and PSP applications.

Palladium Complexation. To side-step the incorporation of $\mathrm{Cu}(\mathrm{II})$ into the porphyrin core during the polymerizations and to enable the synthesis of luminescent polymers, the $\mathrm{Zn}-$ tetrabromoporphyrin (4) was synthesized and employed in the ATRP of methyl methacrylate with a view to the subsequent removal of $\mathrm{Zn}$ after polymerization thereby regenerating the free-base porphyrin (following the approach to $\mathrm{Zn}$-metalated monofunctional porphyrin initiators suggested by de Loos et al.). ${ }^{9 \mathrm{a}}$ The polymerization of MMA in toluene using $\mathrm{Cu}{ }^{\mathrm{I}} \mathrm{Br}, N-(n-$ propyl)-2-pyridylmethanimine and $\mathrm{Zn}$ tetrabromoporphyrin (4) proceeded successfully. After $17 \mathrm{~h}$ and $77 \%$ monomer conversion a PMMA star polymer $(\boldsymbol{P 3})$ was obtained with an $M_{\mathrm{n}}$ of 29450 (close to the theoretical value, Table 1) and a relatively narrow polydispersity $(<1.3)$.

The $\mathrm{Zn}(\mathrm{II})$ could be directly replaced by $\mathrm{Pd}(\mathrm{II})$ in the porphyrin-core star-PMMA (P3) by heating with $\mathrm{Pd}^{\mathrm{II}} \mathrm{Cl}_{2}$ in $\mathrm{DMF}$ at $110{ }^{\circ} \mathrm{C}$ for 7 days (no effort was made to quantify the kinetics of this reaction). UV-vis spectroscopic comparison of the $\mathrm{Zn}$ (II) porphyrin-core star-PMMA (P3) with the $\mathrm{Pd}(\mathrm{II})$ and $\mathrm{Zn}$ (II) tetrabromoporphyrins (3 and $\mathbf{4}$ ) and the resulting $\mathrm{Pd}(\mathrm{II})$ porphyrin-core star-PMMA (Pd-P3) clearly demonstrated the removal of the $\mathrm{Zn}(\mathrm{II})$ by $\mathrm{Pd}(\mathrm{II})$ (Figure 6a). To further demonstrate the utility of this approach to incorporating metals into the cores of these polymers the porphyrin-core star-PIBMTFEMA (P12) was synthesized by the copolymerization of IBMA and TFEMA in toluene using $\mathrm{Cu}$ IBr, $N$-(n-propyl)-2pyridylmethanimine and $\mathrm{Zn}$ tetrabromoporphyrin (4). After $3 \mathrm{~h}$, the reaction became highly viscous and stirring ceased. After workup a Zn porphyrin-core star copolymer of PIBMAco-TFEM (42\% IBMA to 58\% TFEMA by ${ }^{1} \mathrm{H}$ NMR) was obtained in $68 \%$ yield (gravimetric). This copolymer (P12) was heated under reflux conditions with $\mathrm{Pt}^{\mathrm{II}} \mathrm{Cl}_{2}$ in benzonitrile for $72 \mathrm{~h}$ and the resulting $\mathrm{Pt}(\mathrm{II})$ porphyrin-core star-PIBMATFEMA (Pt-P12) displayed a Q-band $\lambda_{\max }$ at $539 \mathrm{~nm}$ by UVvis analysis (Supporting Information).

It was concurrently found that heating polymer $\mathbf{P 1}$ with $\mathrm{PdCl}_{2}$ in $\mathrm{DMF}$ resulted in the incorporation of $\mathrm{Pd}(\mathrm{II})$ to give a predominantly $\mathrm{Pd}(\mathrm{II})$ porphyrin-core star-PMMA. Again this was demonstrated by comparison of the UV-vis spectra of the $\mathrm{Cu}$ (II)/free-base porphyrin-core star-PMMA (P1) with the Pd(II) and $\mathrm{Cu}$ (II) tetrabromoporphyrins (3 and 5) and the resulting Pd(II) porphyrin-core star-PMMA (Pd-P1) (Figure 5b). MALDI-TOF analysis of $\mathbf{P d - P 1}$ data gave an $M_{\mathrm{n}}$ of 41397 and a polydispersity index of 1.09 compared to $M_{\mathrm{n}}=41,043, M_{\mathrm{w}} / M_{\mathrm{n}}$ $=1.11$ by SEC for P1 (chromatogram given in the Supporting Information). For both palladiated porphyrin-core polymers (Pd-P1 and Pd-P3) a strong absorption band ascribable to $\mathrm{Pd}(\mathrm{II})$ complexation was visible at $524 \mathrm{~nm}$ (Table 2, Figure 6b)

Fluorescent Behavior. Both polymers containing $\mathrm{Pd}(\mathrm{II})$ in the porphyrin-core $(\mathbf{P d}-\mathbf{P} \mathbf{1}$ and $\mathbf{P d}-\mathbf{P 3})$ were demonstrated to be fluorescent by spectroscopic analysis of their solutions in tetrahydrofuran (at concentrations of $0.1 \mathrm{~g} \mathrm{dm}^{-3}$ ) (Figure 7a). The Pt(II) porphyrin-core star-PIBMA-TFEMA polymer (PtP12) also showed strong fluorescence in butyl acetate solution (Figure 7b) with $\lambda_{\max }$ at 604, 648, and $860 \mathrm{~nm}$ (excitation $425 \mathrm{~nm})$.

In pressure sensitive paints, the luminescent porphyrin components typically contain $\mathrm{Pd}$ or Pt and are incorporated in the polymer matrices at $1-2$ wt $\%$ of the total solids content. ${ }^{19}$ Whereas the arm lengths of the polymer components in the polymers synthesized in this study were relatively low at the molecular weights achieved, relatively high molecular weight homopolymer samples can be utilized in the paint formulation to provide the oxygen permeable film matrix. Consequently the mechanical properties of the films are not entirely dependent upon the star polymers themselves and the arms provide an 
anchor and solubility within the homopolymer matrix. To demonstrate their potential as fluorescent components in thin films samples of $\mathrm{Pd}(\mathrm{II})$ porphyrin-core star-PMMA were dissolved in solutions of PBMA-PMMA in toluene and PIBMATFEMA in toluene in order to obtain $1 \%$ and $0.1 \mathrm{wt} \%$ of dye content (based on porphyrin core weight to total solids content upon solvent evporation). The mixtures were cast as thin films by air-brush giving orange optically transparent thin films with thicknesses between 14 and $26 \mu \mathrm{m}$. Both gave clear emission maxima at $\sim 600 \mathrm{~nm}$ upon excitation at $404 \mathrm{~nm}$. Representative excitation and emission spectra are shown in Figure 7c.

\section{Conclusion}

This paper demonstrates that ATRP using tetrabromoporphyrin-based initiators in combination with the appropriate reaction conditions and ligands can be employed to synthesize well-defined star polymers from a number of monomers; styrene, methyl methacrylate, methyl acrylate, butyl methacrylate, and octadecyl acrylate. A copolymer of isobutyl methacrylate and trifluoromethacrylate was also synthesized. The main advantage of this approach, using tetrafunctional porphyrin initiators in ATRP, is that the precursor porphyrins are commercially available from a number of sources (e.g., Aldrich, Porphyrin Systems) whereas the monofunctionalized porphyrins are significantly more expensive and of limited availability as a consequence of the low yields resulting from the synthesis of asymmetric porphyrins, giving mixed products. ${ }^{20}$

Whereas the ATRP process results in the partial metalation of the porphyrin core by $\mathrm{Cu}(\mathrm{II})$, this metalation can be avoided by employing a zinc metalloporphyrin initiator. Fluorescent porphyrin-core star polymers can be produced by metal incorporation into the free-base porphyrin star polymers or by transmetalation of the $\mathrm{Zn}$ porphyrins; this was demonstrated by heating the core-porphyrin star-polymer products in appropriate solution of the metal salts $\left(\mathrm{PdCl}_{2}, \mathrm{PtCl}_{2}\right)$. Fluorescence from the palladiated and the platinated metalloporphyrin core starpolymers was demonstrated in solution and for the palladiated materials in thin films in poly(isobutyl methacrylate-co-trifluoroethyl methacrylate) matrices. The photoluminescent properties and applications of the fluorescent star-polymers as the active components in oxygen-sensing paint formulations will be discussed in a forthcoming publication.

Acknowledgment. We would like to acknowledge the financial support of the EPSRC (Grant GR/R37463) for this project.

Supporting Information Available: Figures showing LDITOF and MALDI-TOF analysis of $\mathbf{3}$ and $\mathbf{P 1}$ and Pd-P1), representative ${ }^{1} \mathrm{H}$ NMR spectra (free-base initiator $\mathbf{2}$ and $\mathbf{P 8}$ ), and $\mathrm{UV}$-vis spectra of $\mathbf{P t}-\mathbf{P 1 2}$. This material is available free of charge via the Internet at http://pubs.acs.org.

\section{References and Notes}

(1) (a) Papkovsky, D. B.; O'Riordan, T. C. J. Fluoresc. 2005, 15, 569584. (b) Demas, J. N.; DeGraff, B. A.; Coleman, P. B. Anal. Chem. 1999, 71, 793A-800A.

(2) (a) Gewehr, P. M.; Delpy, D. T. Med. Biol. Eng. Comput. 1993, 31, 2-10. (b) Gewehr, P. M.; Delpy, D. T. Med. Biol. Eng. Comput. 1993 31,11-21. (c) Papkovsky, D. B. Sens. Actuators B 1995, 29, $213-$ 218. (d) Papkovsky, D. B. Anal. Chem. 1995, 67, 4112-4117. (e) Hartmann, P.; Trettnak, W. Anal. Chem. 1996, 68, 2615-2820. (f) Beswick, R. B.; Pitt, C. W. Chem. Phys. Lett. 1996, 143, 589-592. (g) Harriman, A. Platinum Met. Rev. 1990, 34, 181-184. (h) Lee, W. W.-S.; Li, K.-Y.; Leung, Y.-B.; Chan, C.-S.; Chan, K. S. J. Mater Chem. 1993, 3, 1031-1035. (i) Papkovsky, D. B. Sens. Actuators B 1993, 11, 293-300. (j) Kavandi, J.; Callis, J.; Gouterman, M.; Khali, G.; Wright, D.; Green, E. Rev. Sci. Instrum. 1990, 61, 3340-3347. (k) Baron, A. E.; Danielson, J. D. S.; Gouterman, M.; Wan, J. R.; Callis, J. B.; McLachlan, B. Rev. Sci. Instrum. 1993, 64, 3394-3402. (1) Amao, Y.; Tabuchi, Y.; Yamashita, Y.; Kimura, K. Eur. Polym. J. 2002, 38, 675-681. (m) Douglas, P.; Eaton, K. Sens. Actuators B: Chem. 2002, 82, 200-208.

(3) Basu, B. J.; Anandan, C.; Rajam, K. S. Sens. Actuators B 2003, 94 , 257-266.

(4) (a) Hah, H.; Sakai, T.; Asai, K.; Nishide, H. Macromol. Symp. 2003 , 204, 27. (b) Obata, M.; Tanaka, Y.; Araki, N.; Hirohara, S.; Yano, S.; Mitsuo, K.; Asai, K.; Harada, M.; Kakuchi, T.; Ohtsuki, C. J. Polym. Sci., Part A: Polym. Chem. 2005, 43, 2997-3006.

(5) (a) Controlled/"Living" Radical Polymerization: Progress in ATRP, NMR and RAFT, Matyjasewski, K., Ed.; American Chemical Society: Washington, DC, 2000. (b) Kato, M.; Kamigaito, M.; Sawamoto, M.; Higashimura, T. Macromolecules 1995, 28, 1721-1723. (c) Wang, J. S.; Matyjaszewski, K. Macromolecules 1995, 28, 7901-7910. (d) Percec, V.; Barboiu, B. Macromolecules 1995, 28, 7970-7972.

(6) (a) Schubert, U. S. Macromol. Rapid Commun. 2005, 26, 237-237. (b) Tekin, E.; Holder, E.; Marin, V.; de Gans, B-J.; Schubert, U. S Macromol. Rapid Commun. 2005, 26, 293-297. (c) Carlise, J. R. Wang, X. Y.; Weck, M. Macromolecules, 2005, 38, 9000-9008.

(7) (a) Matyjaszewski, K. Polym. Int. 2003, 52, 1559-1565. (b) Kasko, A. M.; Heintz, A. M.; Pugh, C. Macromolecules 1998, 31, 256-271 (c) Matyjaszewski, K.; Miller, P. J.; Fossum, E.; Nakagawa, Y. Appl. Organomet. Chem. 1998, 12, 667-673. (d) Hedrick, J. L.; Trollsas, M.; Hawker, C. J.; Atthoff, B.; Claesson, H.; Heise, A.; Miller, R. D.; Mecerreyes, D.; Jerome, R.; Dubois, P. Macromolecules 1998 $31,8691-8705$

(8) (a) Wu, X. F.; Collings, J. E; McAlvin, J. E.; Cutts, R. W.; Fraser, C. L. Macromolecules 2001, 34, 2812-2821. (b) Smith, A. P.; Fraser, C. L. Macromolecules 2003, 36, 2654-2660. (c) Wu, X. F.; Fraser, C. L. Macromolecules 2000, 33, 4053-4060. (d) Johnson, R. M.; Fraser, C. L. Macromolecules 2004, 37, 2718-2727. (e) Farah, A A.; Pietro, W. J. J. Polym. Sci., Part A: Polym. Chem. 2005, 43, 6057-6072. (f) Viau, L.; Even, M.; Maury, O.; Haddleton, D. M.; Le Bozec, H. Macromol. Rapid Commun. 2003, 24, 630-635.

(9) (a) de Loos, F.; Reynhout, I. C. Cornelissen, J. J. L. M.; Rowan, A E.; Nolte, R. J. M. Chem. Commun. 2005, 60-62. (b) Beil, J. B.; Zimmerman, S. C. Macromolecules 2004, 37, 778-787.

(10) (a) Haddleton, D. M.; Crossman, M. C.; Bogdan, H. D.; Duncalf, D. J.; Heming, A. M.; Kukulj, D.; Shooter, A. J. Macromolecules 1999, 32, 2110-2119. (b) Street, G.; Illsley, D.; Holder, S. J. J. Polym. Sci. Part A: Polym. Chem. 2005, 43, 1129-1143.

(11) The ester linkage may not be an ideal linker for the long application of such materials in certain applications (such as PSPs) where longterm susceptibility to hydrolysis may be an issue. However for the relatively short-term purposes the ester link should be robust enough not to hydrolyse significantly over the time periods envisaged, particularly given the hydrophobic nature of the polymeric component. Should high stability links between the porphrin and polymer arms be necessary other linkers could be utilized following facile chemical reactions generally utilized for porphyrins.

(12) (a) Anderson, H. L.; Wylie, A. P.; Prout, K. J. Chem. Soc., Perkin Trans. 1 1998, 1607-1611. (b) Rothemund, P.; Menotti, A. R. J. Am. Chem. Soc. 1948, 70, 1808.

(13) (a) Papkovsky, D. B.; O'Riordan, T. C. J. Fluoresc. 2005, 15, 569584. (b) Smith, K M. Porphyrins and Metalloporphyrins; Elsevier, Amsterdam, 1975

(14) Matyjaszewski, K.; Xia, J. H. Chem. Rev. 2001, 101, 2921-2990.

(15) Matyjaszewski, K.; Davis, K.; Patten, T. E.; Wei, M. L. Tetrahedron 1997, 53 15321-15329.

(16) (a) Matyjaszewski, K.; Patten, T. E.; Xia, J. J. Am. Chem. Soc. 1997 119, 674-680. (b) Fischer, H. Macromolecules 1997, 30, 5666- 5672 (c) Parker, J; Jones, R. G.; Holder, S. J. Macromolecules 2000, 33, 9166-9168.

(17) (a) Amao, Y.; Miyashita, T.; Okura, I. Analyst 2000, 125, 871-875. (b) Amao, Y.; Miyashita, T.; Okura, I. J. Fluor. Chem. 2001, 107, 101-106. (c) Amao, Y.; Miyashita, T.; Okura, I. J. Porphyrins Phthalocyanines 2001, 5, 433-438. (d) Amao, Y.; Asai, K.; Miyashita, T. Anal. Commun. 1999, 36, 367-369.

(18) (a) Amao, Y.; Miyashita, T.; Okura, I. React. Funct. Polym. 2001, 47, 49-54. (b) Amao, Y.; Asai, K.; Miyashita, T.; Okura, I. Polym. J. 1999, 31, 1267-1269. (c) Amao, Y.; Miyashita, T.; Okura, I. Anal. Chim. Acta. 2000, 421, 167-174.

(19) (a) Khalil, G. E.; Costin, C.; Crafton, J.; Jones, G.; Grenoble, S.; Gouterman, M.; Callis, J. B.; Dalton, L. R. Sens. Actuators B 2004 97, 13-21. (b) Coyle, L. M.; Gouterman, M. Sens. Actuators B 1999, $61,92-99$.

(20) Lindsey, J. S.; Schreimann, I. C.; Hsu, H. C.; Kearney, P. C.; Marguerettaz, A. M. J. Org. Chem. 1987, 52, 827.

MA062870S 